\title{
Фотоаккумулирующие наногетероструктуры на основе диоксида титана
}

\author{
(C) Е.А. Константинова ${ }^{1,2,3}$, В.Б. Зайцев ${ }^{1, \uparrow, ~ E . В . ~ К ы т и н а ~}{ }^{1}$, А.В. Марикуца ${ }^{4}$ \\ ${ }^{1}$ Московский государственный университет им. М.В. Ломоносова (физический фракультет), \\ 119991 Москва, Россия \\ ${ }^{2}$ Национальный исследовательский центр „Курчатовский институт“, \\ 123182 Москва, Россия \\ ${ }^{3}$ Московский физико-технический институт, \\ 141700 Долгопрудный, Россия \\ ${ }^{4}$ Московский государственный университет им. М.В. Ломоносова (химический факультет), \\ 119991 Москва, Россия \\ ฯ E-mail: vzaitsev@phys.msu.ru
}

Поступила в Редакцию 28 сентября 2020 г.

В окончательной редакции 10 октября 2020 г.

Принята к публикации 10 октября 2020 г.

Исследованы наногетероструктуры на основе диоксида титана, синтезированные золь-гель методом. Применялись методы микроскопии, рентгеновской дифракции, оптической спектроскопии и электронного парамагнитного резонанса. Все исследуемые образцы характеризуются большой удельной площадью поверхности ( 100 м² на 1г вещества). Установлено, что основным типом радикалов в полученных структурах являются $\mathrm{N}^{\bullet}, \mathrm{Ti}^{3+}, \mathrm{Mo}^{5+}, \mathrm{V}^{4+}$ и $\mathrm{W}^{5+}$, в зависимости от состава образцов. Показано, что наногетероструктуры, состоящие из нескольких оксидов металлов, обладают высокой фотокаталитической активностью в видимом диапазоне спектра и способностью аккумулировать фотогенерированные носители заряда. Как следствие, каталитические реакции в образцах продолжаются и после выключения освещения. Обнаружена корреляция между скоростью фотокатализа, спектрами поглощения в видимой области и концентрацией радикалов в исследуемых структурах. Полученные результаты могут быть использованы для разработки на основе наногетероструктур, состоящих из нанооксидов титана, молибдена, вольфрама, ванадия в различной комбинации, энергоэффективных каталитических устройств, работающих при периодическом освещении в видимом диапазоне спектра.

Ключевые слова: оксид титана, оксид молибдена, оксид ванадия, оксид вольфрама, накопление заряда, фотокатализ, наногетероструктуры.

DOI: $10.21883 /$ FTP.2021.02.50504.9503

\section{1. Введение}

В настоящее время в научном сообществе активно ведутся работы по преодолению недостатков $\mathrm{TiO}_{2}$, на протяжении многих лет остающегося одним из основных фотокаталитических материалов. Сначала остановимся на достоинствах данного материала. Пристальный интерес к $\mathrm{TiO}_{2}$ обусловлен его специфическими свойствами, среди которых можно выделить высокую фотокаталитическую активность и весьма развитую поверхность (открытую для воздействия молекул окружающей среды), с удельной площадью от десятков до сотен ${ }^{2}$ на 1г вещества в зависимости от метода синтеза [1-3]. За счет фотокатализа на поверхности $\mathrm{TiO}_{2}$ органические вещества (в том числе токсичные), а также вирусы и бактерии, контактирующие с ней, разлагаются до простых составляющих - углекислого газа и воды [3-6]. Движущей силой фотокатализа (т.е. окислительно-восстановительных реакций) является эффективная генерация в $\mathrm{TiO}_{2}$ радикалов под действием света за счет взаимодействия адсорбированных на поверхности молекул воды и кислорода с фотовозбужденными носителями заряда.
Большим недостатком $\mathrm{TiO}_{2}$ как катализатора является необходимость постоянной подсветки в ультрафиолетовой (УФ) области спектра. Усилия исследователей направлены на увеличение его коэффициента поглощения в видимой области спектра, для того чтобы заменить УФ освещение на излучение видимого диапазона. Для этого $\mathrm{TiO}_{2}$ подвергают легированию атомами различных элементов [7-9]. Еще один способ усовершенствования фотокаталитических характеристик - это увеличение времени жизни фотовозбужденных носителей заряда (электронов и дырок) в результате их пространственного разделения в наночастицах катализатора, препятствующего рекомбинации. Вследствие этого отпадает необходимость постоянной подсветки. Для достижения указанной цели диоксид титана комбинируют с полупроводниковыми оксидами других металлов [10-12].

Настоящая работа представляет комплексный подход к синтезу наноматериалов на основе $\mathrm{TiO}_{2}$. Новый подход сочетает в себе легирование диоксида титана (для повышения его чувствительности к видимому излучению) с созданием на основе легированного $\mathrm{TiO}_{2}$ наногетероструктур, включающих наночастицы других металлооксидов, так же обладающих фотокаталитическими свой- 
ствами. В работе удалось получить наногетероструктуры, эффективно поглощающие излучение в видимой области спектра и аккумулирующие фотовозбужденные носители заряда, что обеспечивает достаточно длительную каталитическую активность полученных структур после выключения освещения.

\section{2. Материалы и методы}

Легированный азотом нанокристаллический диоксид титана в форме водного золя готовили методом контролируемого гидролиза, добавляя по каплям 12.5\% $\mathrm{NH}_{4} \mathrm{OH}$ к $2.5 \mathrm{M}$ водному раствору $\mathrm{TiCl}_{4}+0.65 \mathrm{M} \mathrm{HCl}$, охлажденному до $0^{\circ} \mathrm{C}$, при интенсивном перемешивании до достижения $\mathrm{pH} \approx 5$. Полученный осадок промывали дистиллированной водой и диспергировали ультразвуковой обработкой. Затем осадок геля помещали в сушильный шкаф в чашке, отжигали в печи при $450^{\circ} \mathrm{C}$ и растирали. Для получения нанооксидов молибдена, ванадия, вольфрама использовались прекурсоры $\left(\mathrm{NH}_{4}\right)_{6} \mathrm{Mo}_{7} \mathrm{O}_{24}$ (парамолибдат аммония), $\mathrm{NH}_{4} \mathrm{VO}_{3}$ (метаванадат аммония), $\left(\mathrm{NH}_{4}\right)_{10} \mathrm{~W}_{12} \mathrm{O}_{41} \cdot 4.5 \mathrm{H}_{2} \mathrm{O}$ (паравольфрамат аммония) соответственно. Для получения наногетероструктур $\mathrm{TiO}_{2} / \mathrm{MoO}_{3}, \quad \mathrm{TiO}_{2} / \mathrm{V}_{2} \mathrm{O}_{5}, \quad \mathrm{TiO}_{2} / \mathrm{WO}_{3}, \quad \mathrm{TiO}_{2} / \mathrm{MoO}_{3} / \mathrm{WO}_{3}$, $\mathrm{TiO}_{2} / \mathrm{MoO}_{3} / \mathrm{V}_{2} \mathrm{O}_{5}, \quad \mathrm{TiO}_{2} / \mathrm{MoO}_{3} / \mathrm{WO}_{3}$ растворяли $\left(\mathrm{NH}_{4}\right)_{6} \mathrm{Mo}_{7} \mathrm{O}_{24}, \mathrm{NH}_{4} \mathrm{VO}_{3}$ или $\left(\mathrm{NH}_{4}\right)_{10} \mathrm{~W}_{12} \mathrm{O}_{41} \cdot 4.5 \mathrm{H}_{2} \mathrm{O}$ в смеси соляной кислоты и пероксида водорода, перемешивали эти растворы с осажденным легированным $\mathrm{TiO}_{2}$, затем высушивали и отжигали при $400^{\circ} \mathrm{C}$.

Морфологию полученных образцов изучали методом сканирующей электронной микроскопии с использованием JSM7600F (JEOL, Япония). Исследования дифракции рентгеновских лучей (XRD) проводили с помощью дифрактометра ДРОН-4 (Буревестник, Россия) $\left(\mathrm{Cu} K_{\alpha}\right.$-излучение). Размеры областей когерентного рассеяния (размеры частиц) определяли по формуле Шеррера, используя полную ширину на половине максимума пиков, приборное уширение составляло $0.09^{\circ}$. Для определения удельной поверхности использован метод низкотемпературной адсорбции азота (метод Брунауэра-Эммета-Теллера, метод БЭТ) (прибop Chemisorb 2750, Micromeritics).

Спектры диффузного отражения регистрировали с использованием спектрометра LS-55 Perkin Elmer (США) (спектральный диапазон от 250 до 900 нм). Фотокаталитическая активность (окислительная способность) образцов была изучена с использованием реакции фотодеградации красителя родамина 6G. Для этого краситель наносили на поверхность образцов из водного раствора. Изменения поверхностной концентрации красителя контролировали по величине диффузного отражения $R$ на длине волны 530 нм, что соответствует максимальному поглощению адсорбированного красителя. Световой фильтр YG-16 из желтого стекла использовался для получения видимого спектрального диапазона (от 450 до 750 нм). Затем диффузное отражение было пересчитано в значение, пропорциональное поверхностной концентрации, с использованием подхода Кубелки-Мунка [13].
Средний диаметр наночастиц $\mathrm{TiO}_{2} d$ в наногетероструктурах, рассчитанный по формуле Шеррера из уширения соответствующих рефлексов, и удельная площадь поверхности, $S_{s}$

\begin{tabular}{l|r|r}
\hline \multicolumn{1}{c|}{ Образец } & $d, \mathrm{HM}$ & $S_{s}, \mathrm{M}^{2} / \Gamma$ \\
\hline $\mathrm{TiO}_{2}$ & 14 & 90 \\
$\mathrm{TiO}_{2} / \mathrm{MoO}_{3}$ & 4 & 110 \\
$\mathrm{TiO}_{2} / \mathrm{MoO}_{3} / \mathrm{WO}_{3}$ & 4 & 100 \\
$\mathrm{TiO}_{2} / \mathrm{MoO}_{3} / \mathrm{V}_{2} \mathrm{O}_{5}$ & 9 & 95 \\
$\mathrm{TiO}_{2} / \mathrm{WO}_{3}$ & 9 & 98
\end{tabular}

Спектры электронного парамагнитного резонанса (ЭПР) регистрировали на спектрометре ELEXSYS-E500 (Bruker, Германия) (Х-диапазон, чувствительность до $10^{10}$ спин/г). Концентрацию парамагнитных центров (ПЦ) оценивали с использованием монокристалла $\mathrm{CuCl}_{2} \cdot 2 \mathrm{H}_{2} \mathrm{O}$ с известным числом спинов в качестве стандарта.

\section{3. Результаты и обсуждение}

На рис. 1 показаны микрофотографии исходного $\mathrm{TiO}_{2}$ и наногетероструктур на его основе. Исследуемые образцы представляют собой сгруппированные в агломераты наночастицы.

На рис. 2 показаны дифрактограммы для наногетероструктур. С учетом положения дифракционных пиков и их уширения были определены фазовый состав образцов и средний размер нанокристаллов в них.

Все наногетероструктуры содержат только одну фазу $\mathrm{TiO}_{2}$ - анатаз, о чем свидетельствуют положения рефлексов. На дифрактограммах для $\mathrm{TiO}_{2} / \mathrm{MoO}_{3}$, $\mathrm{TiO}_{2} / \mathrm{WO}_{3}, \mathrm{TiO}_{2} / \mathrm{MoO}_{3} / \mathrm{WO}_{3}, \mathrm{TiO}_{2} / \mathrm{MoO}_{3} / \mathrm{V}_{2} \mathrm{O}_{5}$ возможно присутствие фаз гексагонального $\mathrm{MoO}_{3}$ и моноклинного $\mathrm{WO}_{3}$ в соответствующих образцах, но их пики явно невозможно различить из-за малой интенсивности и перекрывания с пиками основной фазы - анатаза. Наличие фазы $\mathrm{V}_{2} \mathrm{O}_{5}$ однозначно не установлено рентгенофазовым анализом в образцах $\mathrm{TiO}_{2} / \mathrm{V}_{2} \mathrm{O}_{5}$ и $\mathrm{TiO}_{2} / \mathrm{MoO}_{3} / \mathrm{V}_{2} \mathrm{O}_{5}$, вероятно, из-за отсутствия и (или) слишком малой интенсивности пиков в ожидаемых для орторомбической фазы $\mathrm{V}_{2} \mathrm{O}_{5}$ положениях. В силу вышесказанного удалось определить средний диаметр $d$ (размер ОКР) только нанокристаллов диоксида титана во всех образцах (см. таблицу). В таблице представлена также определенная с помощью метода низкотемпературной адсорбции азота (БЭТ) удельная площадь поверхности наногетероструктур.

Как видно из таблицы, в наногетероструктурах размеры наночастиц $\mathrm{TiO}_{2}$ уменьшаются по сравнению с чистым диоксидом титана. Это обусловлено, вероятно, тем, что другие оксиды металлов в составе гетероструктур препятствуют диффузии ионов основной фазы и тем самым затрудняют кристаллизацию $\mathrm{TiO}_{2}$ в ходе отжига титановой кислоты. 

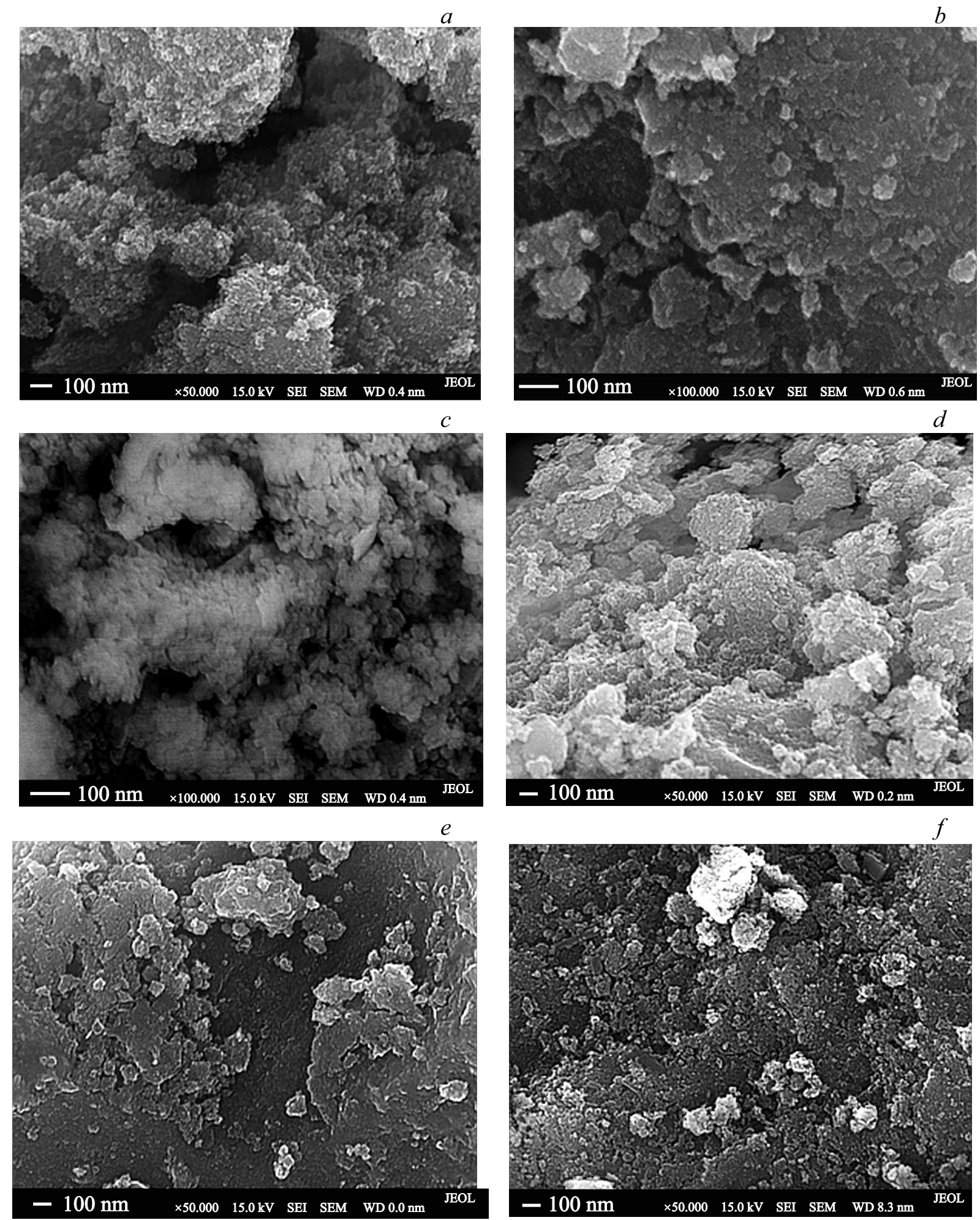

Рис. 1. Микрофотографии исходного $\mathrm{TiO}_{2}(a)$ и наногетероструктур $\mathrm{TiO}_{2} / \mathrm{MoO}_{3} \quad(b), \mathrm{TiO}_{2} / \mathrm{V}_{2} \mathrm{O}_{5} \quad(c)$, $\mathrm{TiO}_{2} / \mathrm{WO}_{3} \quad(d)$, $\mathrm{TiO}_{2} / \mathrm{MoO}_{3} / \mathrm{WO}_{3}(e)$ и $\mathrm{TiO}_{2} / \mathrm{MoO}_{3} / \mathrm{V}_{2} \mathrm{O}_{5}(f)$. Длина масштабных отрезков 100 нм.

Как легирование азотом диоксида титана, так и создание на его основе наногетероструктур могут сильно изменить оптические свойства материала. Поэтому необходимо было определить оптическую ширину запре- щенной зоны полученных образцов. Данная процедура проводилась с использованием спектров диффузного отражения в диапазоне длин волн от 250 до 700 нм аналогично $[14,15]$ с применением теории Кубелки-Мунка. 


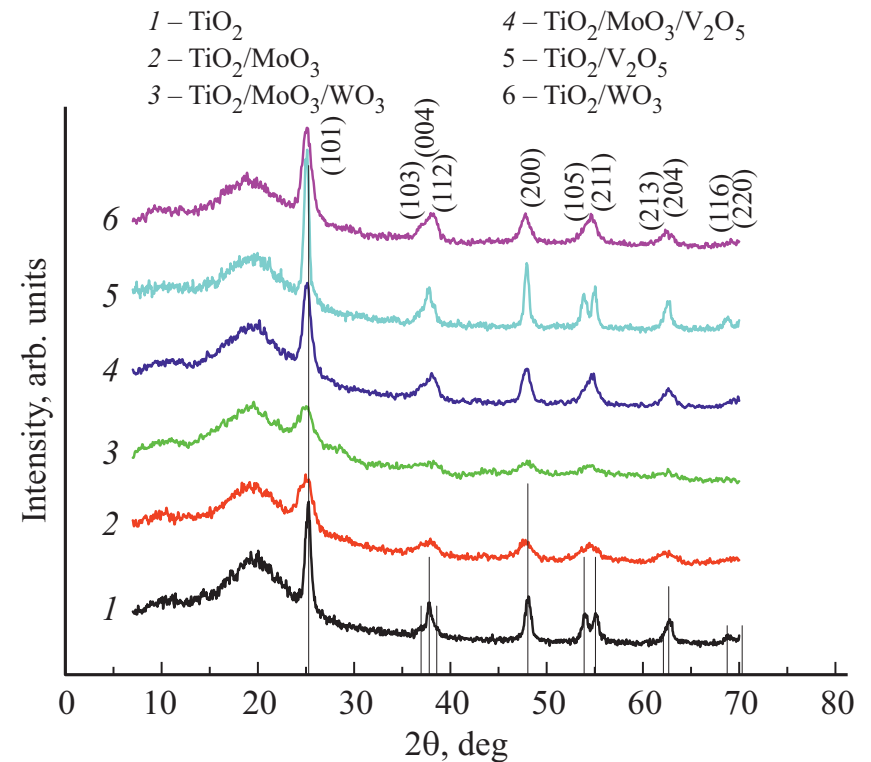

Pис. 2. Дифрактограммы наногетероструктур. Вертикальными прямыми показаны ожидаемые положения рефлексов с соответствующими индексами Миллера для фазы анатаза.

Согласно данной теории, диффузное отражение $R$ образца зависит только от отношения коэффициента поглощения $\alpha$ и коэффициента рассеяния $S$, а не отдельно от коэффициента рассеяния или коэффициента поглощения:

$$
\frac{\alpha}{S}=\frac{(1-R)^{2}}{2 R}=F(R)
$$

где $F(R)$ - функция Кубелки-Мунка.

По результатам диффузного отражения с использованием спектра эталонного белого образца были получены спектры поглощения света для исследованных наноструктур. Для определения ширины запрещенной зоны экспериментальные данные представлены в виде зависимости

$$
(\alpha h v)^{2}=A(h v),
$$

где $A-$ константа, $h$ - постоянная Планка, $h v-$ энергия фотона. Ширина запрещенной зоны $E_{g}$ определялась как точка пересечения линейной экстраполяции данной зависимости с осью энергий фотонов. Такой подход должен применяться для полупроводников с прямыми межзонными переходами, но было неоднократно показано, что он дает достоверные результаты для нанопорошков диоксида титана. Объяснение состоит в том что за счет размерного эффекта может несколько изменяться структура кристаллической решетки при уменьшении объема вещества, что в свою очередь может привести к возникновению прямых межзонных переходов. На подобную возможность указывает, например, широко известный факт резкого увеличения интенсивности фотолюминесценции кремния при переходе от объемного к нанокристаллическому материалу. Превращение непрямозонного полупроводника в прямозонный при этом обычно описывается с точки зрения теории функционала плотности (DFT) - cм., например, [16].

Построение функции Кубелки-Мунка для $\mathrm{TiO}_{2}$, легированного азотом, позволяет определить оптическую ширину запрещенной зоны: $E_{g}=(3.22 \pm 0.01)$ эВ (рис. 3).

Ширина запрещенной зоны нанооксида молибдена, по литературным данным (см., например, [17,18]), существенно различается: от значений $\sim 3$ эВ, близких к характерным для диоксида титана, до гораздо более высоких значений, 23.86 эВ. Определение оптической ширины запрещенной зоны гетероструктуры $\mathrm{TiO}_{2} / \mathrm{MoO}_{3}$ осложнено наличием дополнительной полосы поглощения $\mathrm{MoO}_{3}$ в интервале длин волн $\lambda=330-400$ нм с максимумом при $\lambda=350 \mathrm{Hм}$.

Поскольку $\mathrm{WO}_{3}$ является заметно непрямозонным полупроводником с шириной запрещенной зоны 2.6-3.0 эВ (по литературным данным, - см., например, [19]), поглощение УФ излучения в использованных нами наногетероструктурах, включающих оксид вольфрама, обусловлено главным образом непрямыми переходами электронов из валентной зоны в зону проводимости $\mathrm{WO}_{3}$. Это связано с тем, что ширина запрещенной зоны остальных компонентов указанных гетероструктур несколько выше.
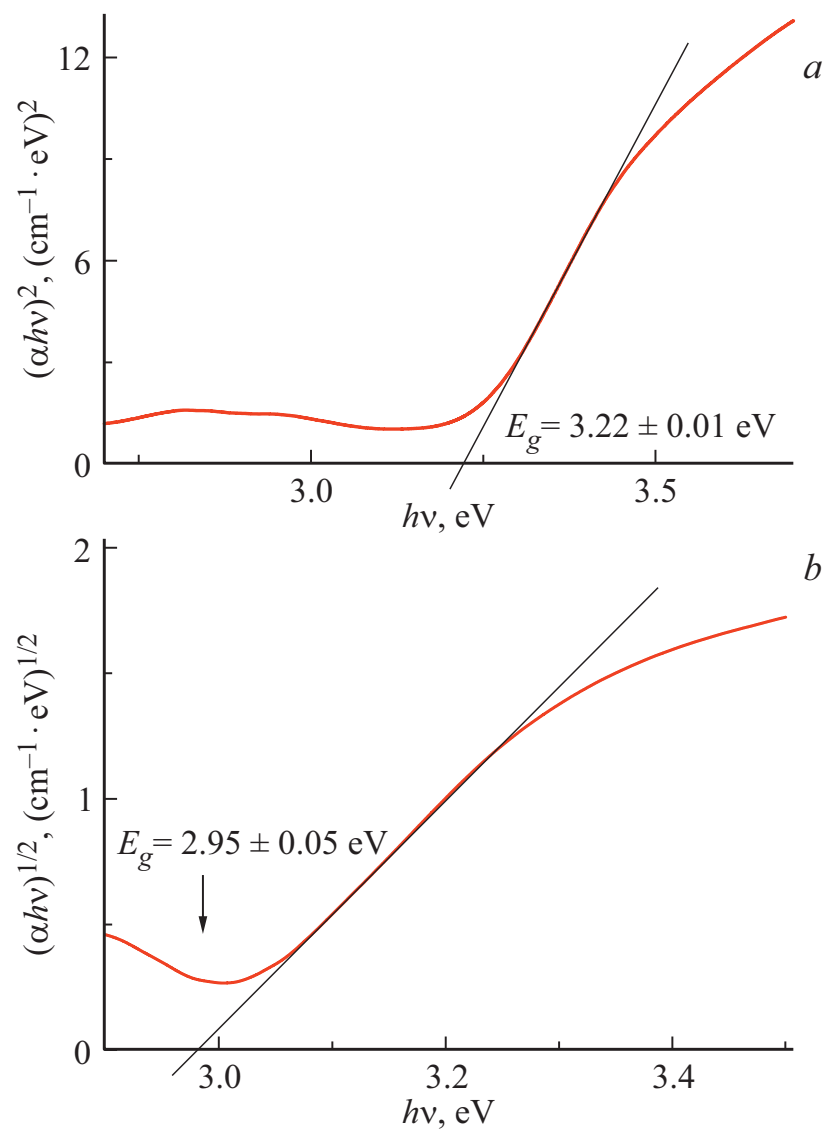

Рис. 3. Определение ширины запрещенной зоны $\mathrm{TiO}_{2}$, легированного азотом $(a)$, и образцов $\mathrm{TiO}_{2} / \mathrm{WO}_{3}(b)$. 
Поэтому для таких образцов ширину запрещенной зоны $E_{g}$ оценивали согласно известному соотношению для непрямозонных переходов:

$$
(\alpha h v)^{1 / 2}=\operatorname{const}\left(h v-E_{g}\right) .
$$

Значение $E_{g}$ соответствует точке пересечения экстраполированного линейного участка зависимости $(\alpha h v)^{1 / 2}$ от энергии с осью абсцисс $h v$ (рис. $3, b$ ). На рис. $3, b$ в качестве примера показано построение спектров в соответствующих координатах для определения ширины запрещенной зоны наногетероструктуры $\mathrm{TiO}_{2} / \mathrm{WO}_{3}$. Ширина запрещенной зоны для $\mathrm{TiO}_{2} / \mathrm{WO}_{3}$ составляет $(2.95 \pm 0.05)$ эВ. Ширина запрещенной зоны для $\mathrm{TiO}_{2} / \mathrm{MoO}_{3} / \mathrm{WO}_{3}$ оказалась близкой к значению $E_{g}$ для $\mathrm{TiO}_{2} / \mathrm{WO}_{3}$.

Для образцов $\mathrm{TiO}_{2} / \mathrm{V}_{2} \mathrm{O}_{5}$ оптическое поглощение, судя по результатам измерений, определяется шириной запрещенной зоны оксида ванадия. При построении функции Кубелки-Мунка для наногетероструктур $\mathrm{TiO}_{2} / \mathrm{V}_{2} \mathrm{O}_{5}$ удалось оценить, что край полосы оптического поглощения определяется величиной $E_{g}=(2.5 \pm 0.2)$ эВ, характерной для оксида ванадия. Аналогичные результаты получены для тройной наногетероструктуры $\mathrm{TiO}_{2} / \mathrm{MoO}_{3} / \mathrm{V}_{2} \mathrm{O}_{5}$.

Легирование и образование наногетероструктур могут не только изменять ширину запрещенной зоны, но также создавать дополнительные центры поглощения излучения и изменять коэффициент поглощения образцов в видимой части спектра. Мы провели сравнительное исследование разности спектров поглощения наногетероструктур различного состава и исходного нелегированного материала $\mathrm{TiO}_{2}$.

Легирование диоксида титана атомами азота приводит к появлению дополнительной линии поглощения в видимой области спектра. Соответствующий разностный спектр коэффициента поглощения $\Delta \alpha(\lambda)$ приведен на рис. 4, $a$ (кривая 1). Из рисунка видно, что легирование азотом приводит к увеличению коэффициента поглощения $\mathrm{TiO}_{2}$ на $0.06-0.09 \mathrm{~cm}^{-1}$ в диапазоне $450-650$ нм. Результирующее превышение поглощения света двойными и тройными наногетероструктурами в видимой области спектра по сравнению с чистым нанопорошком $\mathrm{TiO}_{2}$ также представлено на рис. 4. Из рис. 4, $a$ видно, что коэффициент поглощения видимого излучения существенно выше для гетероструктуры $\mathrm{TiO}_{2} / \mathrm{MoO}_{3}$ (кривая 2), чем для легированного диоксида титана. Видно также, что добавление $\mathrm{MoO}_{3}$ к образцам существенно продлевает спектр поглощения данных образцов в красную область.

Из рис. 4 в целом видно, что тройные наногетероструктуры поглощают видимое излучение эффективнее по сравнению с двойными и тем более по сравнению с порошком легированного азотом диоксида титана. Однако этим преимущество тройных наногетеоструктур не ограничивается. Они обладают существенно лучшими
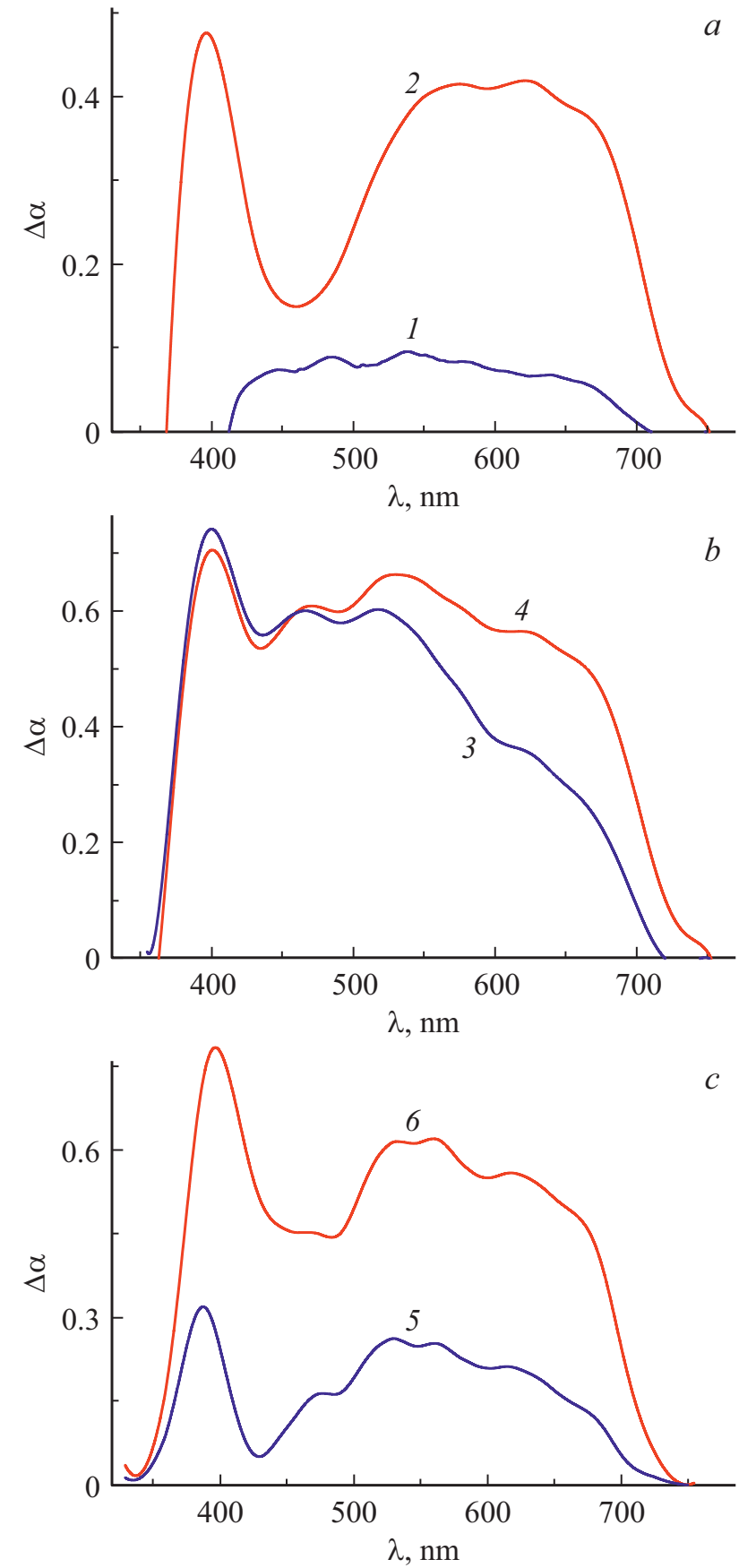

Рис. 4. Результирующее превышение коэффициента поглощения света в видимой области спектра исследуемых образцов по сравнению с чистым нанопорошком $\mathrm{TiO}_{2}$. Образцы: $a$ - легированный азотом $\mathrm{TiO}_{2}(1)$ и $\mathrm{TiO}_{2} / \mathrm{MoO}_{3}(2) ; b-$ $\mathrm{TiO}_{2} / \mathrm{V}_{2} \mathrm{O}_{5}$ (3) и $\mathrm{TiO}_{2} / \mathrm{MoO}_{3} / \mathrm{V}_{2} \mathrm{O}_{5}(4) ; c-\mathrm{TiO}_{2} / \mathrm{WO}_{3}$ (5) и $\mathrm{TiO}_{2} / \mathrm{MoO}_{3} / \mathrm{WO}_{3}$ (6). Образцы наногетероструктур содержат $\mathrm{TiO}_{2}$, легированный азотом.

фотокаталитическими характеристиками по сравнению с другими образцами.

Результаты по фотокатализу на исследованных структурах представлены на рис. 5 и 6 . Эффективность фотокаталического процесса мы оценивали по степени 

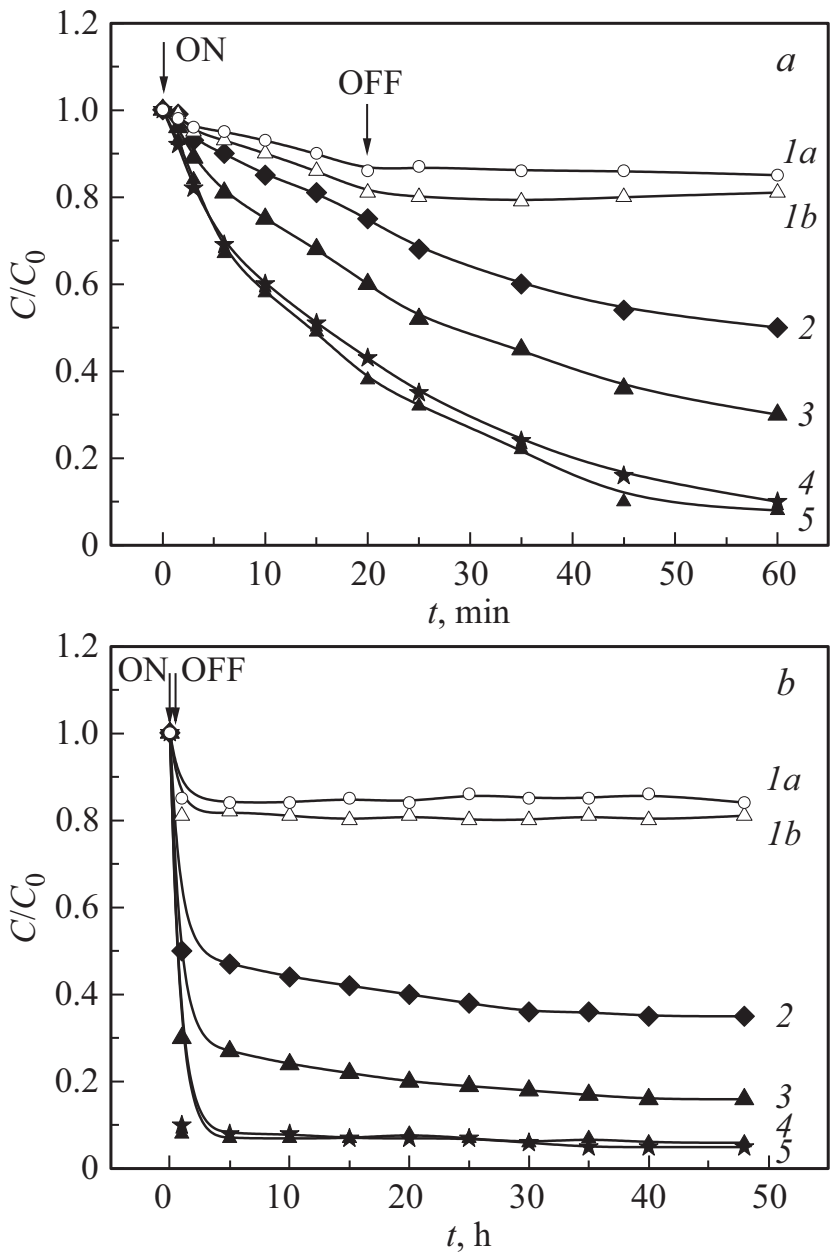

Рис. 5. Кривые кинетики фотокатализа в течение $1(a)$ и 48 ч $(b)$ для нанооксидов $\mathrm{MoO}_{3}(1 a), \mathrm{TiO}_{2}(1 b)$ и наногетероструктур $\mathrm{TiO}_{2} / \mathrm{WO}_{3}$ (2), $\mathrm{TiO}_{2} / \mathrm{MoO}_{3}$ (3), $\mathrm{TiO}_{2} / \mathrm{MoO}_{3} / \mathrm{V}_{2} \mathrm{O}_{5}$ (4), $\mathrm{TiO}_{2} / \mathrm{MoO}_{3} / \mathrm{WO}_{3}$ (5) при фотовозбуждении в видимом диапазоне спектра (450-750 нм). Стрелками показаны моменты включения $(t=0)$ и выключения освещения $(t=20$ мин). $C_{0}-$ концентрация красителя в момент времени $t=0$, $C-$ концентрация красителя в момент времени $t$. Образцы легированы азотом.

разрушения молекул органического красителя. На рисунках показана кинетика фотокатализа, т.е. зависимости от времени $t$ отношения текущей концентрации $C$ тестового красителя родамина $6 \mathrm{G}$ на поверхности наноструктур к его исходной концентрации $C_{0}$ (до включения освещения).

Наибольшей скоростью фотокатализа в видимом диапазоне спектра обладают образцы, состоящие из трех оксидов: $\mathrm{TiO}_{2} / \mathrm{MoO}_{3} / \mathrm{V}_{2} \mathrm{O}_{5}$ и $\mathrm{TiO}_{2} / \mathrm{MoO}_{3} / \mathrm{WO}_{3}$ (рис. 5). Это может быть обусловлено как высокой концентрацией радикалов, участвующих в окислительно-восстановительных реакциях на поверхности фотокатализатора, так и более низкой скоростью рекомбинации фотовозбужденных электронов и дырок. После выключения освещения процесс деградации красителя в наногетероструктурах
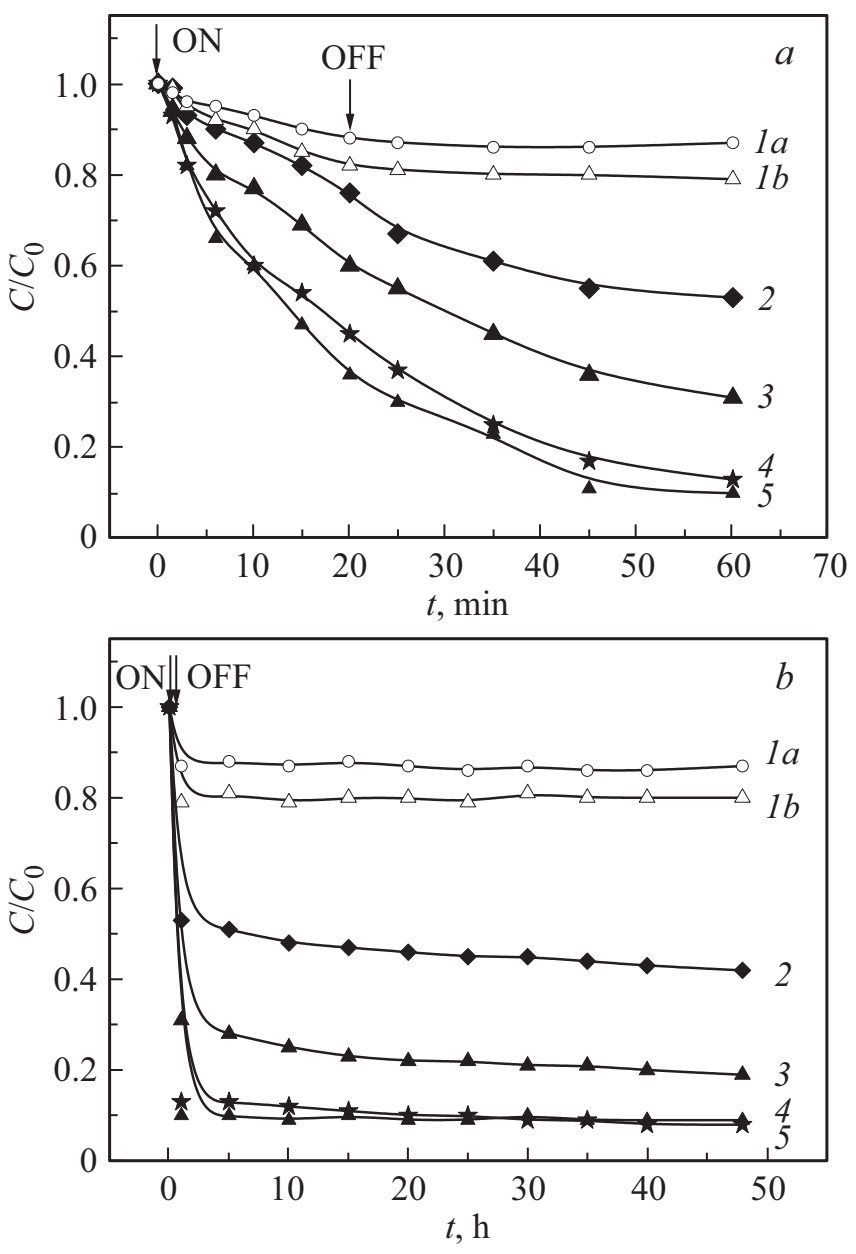

Рис. 6. Кинетики фотокатализа в течение $1(a)$ и 48 ч $(b)$ для нанооксидов $\mathrm{MoO}_{3}(1 a), \mathrm{TiO}_{2}(1 b)$ и наногетероструктур $\mathrm{TiO}_{2} / \mathrm{WO}_{3}$ (2), $\mathrm{TiO}_{2} / \mathrm{MoO}_{3}$ (3), $\mathrm{TiO}_{2} / \mathrm{MoO}_{3} / \mathrm{V}_{2} \mathrm{O}_{5}$ (4), $\mathrm{TiO}_{2} / \mathrm{MoO}_{3} / \mathrm{WO}_{3}$ (5) при фотовозбуждении в диапазоне 450-900 нм через 15 месяцев после синтеза. Стрелками показаны моменты включения $(t=0)$ и выключения освещения $(t=20$ мин $) . C_{0}-$ концентрация красителя в момент времени $t=0, C-$ концентрация красителя в момент времени $t$. Образцы хранились при температуре $300 \mathrm{~K}$.

продолжается (рис. 5), что свидетельствует о подавлении рекомбинации электронов и дырок. Действительно, можно предположить, что после генерации под действием света электронно-дырочных пар в диоксиде титана электроны инжектируются в другие оксиды металлов $\left(\mathrm{MoO}_{3}, \mathrm{~V}_{2} \mathrm{O}_{5}, \mathrm{WO}_{3}\right)$, входящие в состав образцов, и захватываются в них дефектами - ионами молибдена, ванадия или вольфрама. Дырки, оставшиеся в $\mathrm{TiO}_{2}$, теперь не имеют пары для рекомбинации. Таким образом, происходит накопление фотоиндуцированного заряда в наногетероструктурах, который после выключения освещения постепенно расходуется на образование кислородных и гидроксильных радикалов из адсорбированных на поверхности нанооксидов молекул кислорода и воды. Образовавшиеся радикалы продолжают участвовать в 


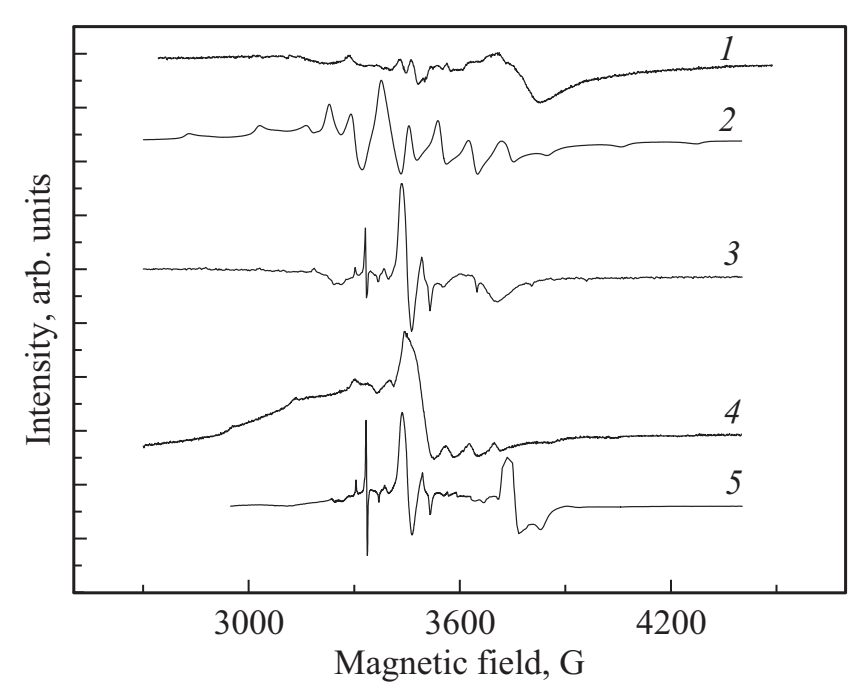

Рис. 7. Спектры ЭПР наногетероструктур $\mathrm{TiO}_{2} / \mathrm{WO}_{3}$ (1), $\begin{array}{lllll}\mathrm{TiO}_{2} / \mathrm{V}_{2} \mathrm{O}_{5} & \text { (2), } & \mathrm{TiO}_{2} / \mathrm{MoO}_{3} & \text { (3), } & \mathrm{TiO}_{2} / \mathrm{MoO}_{3} / \mathrm{V}_{2} \mathrm{O}_{5}\end{array}$ $\mathrm{TiO}_{2} / \mathrm{MoO}_{3} / \mathrm{WO}_{3}(5)$.

окислительно-восстановительных реакциях на поверхности образцов, продлевая тем самым процесс деградации красителя, т.е. каталитическое действие полученных наногетероструктур.

Далее для сравнения также показан пример деградации красителя на наноструктурированных одиночных оксидах титана и молибдена (рис. 5, кривые $1 a$ и $1 b$ ). После выключения освещения процесс деградации красителя на таких образцах прекращался.

Периодический контроль в течение 15 месяцев (не менее 2 раз в месяц) на предмет деградации фотокаталитических свойств наногетероструктур в зависимости от времени хранения показал, что изменения скорости фотокатализа в процессе хранения легированных азотом образцов не превышали $10 \%$, что лежит в диапазоне погрешности измерений. Таким образом, исследуемые образцы характеризуются стабильными фотокаталитическими свойствами в процессе хранения. Это иллюстрирует рис. 6, на котором представлены в качестве примера данные по фотокатализу для наногетероструктур, полученные спустя 15 месяцев после регистрации зависимостей, представленных на рис. 5.

Поскольку дефекты в полупроводниках активно взаимодействуют с фотовозбужденными носителями заряда, нами были выполнены исследования полученных образцов методом ЭПР. Спектры ЭПР наногетероструктур $\mathrm{TiO}_{2} / \mathrm{WO}_{3}, \mathrm{TiO}_{2} / \mathrm{V}_{2} \mathrm{O}_{5}, \mathrm{TiO}_{2} / \mathrm{MoO}_{3}, \mathrm{TiO}_{2} / \mathrm{MoO}_{3} / \mathrm{V}_{2} \mathrm{O}_{5}$, $\mathrm{TiO}_{2} / \mathrm{MoO}_{3} / \mathrm{WO}_{3}$ показаны на рис. 7 и представляют собой суперпозицию сигналов ЭПР от различных радикалов. Для определения параметров радикалов была использована программа „Симфония“ (фирма „Брукер“). Получены следующие параметры линий ЭПР: $g$-тензор $-g_{1}=2.0082, g_{2}=2.0039$, $g_{3}=2.0036$; константы сверхтонкого взаимодействия
(СТВ $)-A_{1}=1.6 \mathrm{G}, A_{2}=1.1 \mathrm{G}, A_{3}=22.5 \mathrm{G}$. Сигналы ЭПР с такими параметрами, в соответствии с литературными данными $[20,21]$, можно отнести к атомам азота $\mathrm{N}^{\bullet}$ (ядерный спин $I=1$ ) с некомпенсированным спином электрона, которые были внедрены в структуру $\mathrm{TiO}_{2}$ в процессе синтеза. Далее нами были идентифицированы центры $\mathrm{Ti}^{3+} /$ кислородная вакансия $-g_{1}=1.9935, g_{2}=1.9328[22]$; $\mathrm{Mo}^{5+}$-радикалы $g_{1}=1.943, g_{2}=1.863, A_{1}=45 \Gamma \mathrm{c}, A_{2}=15 \Gamma \mathrm{c}[21,23]$; $\mathrm{W}^{5+}$-радикалы $-g_{1}=1.78, g_{2}=1.56, g_{3}=1.4[24,25]$; $\mathrm{V}^{4+}$-радикалы $-g_{1}=1.993, g_{2}=1.949, A_{1}=53 \Gamma \mathrm{c}$, $A_{2}=150$ Гс $[22,26,27]$.

Таким образом, в образцах $\mathrm{TiO}_{2} / \mathrm{WO}_{3}$ были обнаружены следующие радикалы: $\mathrm{N}^{\bullet}, \mathrm{Ti}^{3+} /$ кислородная вакансия, $\mathrm{W}^{5+}$. В $\mathrm{TiO}_{2} / \mathrm{V}_{2} \mathrm{O}_{5}$ детектируются центры $\mathrm{N}^{\bullet}, \mathrm{Ti}_{3+} /$ кислородная вакансия, $\mathrm{V}^{4+}$. В наногетероструктурах $\mathrm{TiO}_{2} / \mathrm{MoO}_{3}$ присутствуют дефекты $\mathrm{N}^{\bullet}$, $\mathrm{Ti}^{3+} /$ кислородная вакансия, $\mathrm{Mo}^{5+}$. Наногетероструктуры $\mathrm{TiO}_{2} / \mathrm{MoO}_{3} / \mathrm{V}_{2} \mathrm{O}_{5}$ характеризовались суперпозицией таких спиновых центров, как $\mathrm{N}^{\bullet}, \mathrm{Ti}^{3+} /$ кислородная вакансия, $\mathrm{Mo}^{5+}, \mathrm{V}^{4+}$. В образцах $\mathrm{TiO}_{2} / \mathrm{MoO}_{3} / \mathrm{WO}_{3}$ были обнаружены радикалы $\mathrm{N}^{\bullet}, \mathrm{Ti}^{3+} /$ кислородная вакансия, $\mathrm{Mo}^{5+}, \mathrm{W}^{5+}$. Рассчитанные нами концентрации дефектов $N_{s}$ имели следующие значения: $1.2 \cdot 10^{18}\left(\mathrm{TiO}_{2} / \mathrm{WO}_{3}\right)$, $2.2 \cdot 10^{18}\left(\mathrm{TiO}_{2} / \mathrm{V}_{2} \mathrm{O}_{5}\right), 2 \cdot 10^{18}\left(\mathrm{TiO}_{2} / \mathrm{MoO}_{3}\right), 1.5 \cdot 10^{19}$ $\left(\mathrm{TiO}_{2} / \mathrm{MoO}_{3} / \mathrm{V}_{2} \mathrm{O}_{5}\right), 1.3 \cdot 10^{19} \Gamma^{-1}\left(\mathrm{TiO}_{2} / \mathrm{MoO}_{3} / \mathrm{WO}_{3}\right)$.

Сравнительный анализ спектров поглощения, концентраций дефектов и кинетики фотокатализа для разных наногетероструктур показал, что образцы $\mathrm{TiO}_{2} / \mathrm{MoO}_{3} / \mathrm{V}_{2} \mathrm{O}_{5}$ и $\mathrm{TiO}_{2} / \mathrm{MoO}_{3} / \mathrm{WO}_{3}$ имеют наибольшие значения $N_{s}$, наибольшее поглощение света в видимой области и наибольшую фотокаталитическую активность. Можно сделать вывод, что наблюдается антикорреляция между остаточной концентрацией тестового красителя и концентрацией радикалов в наногетероструктурах. Данный результат пред-

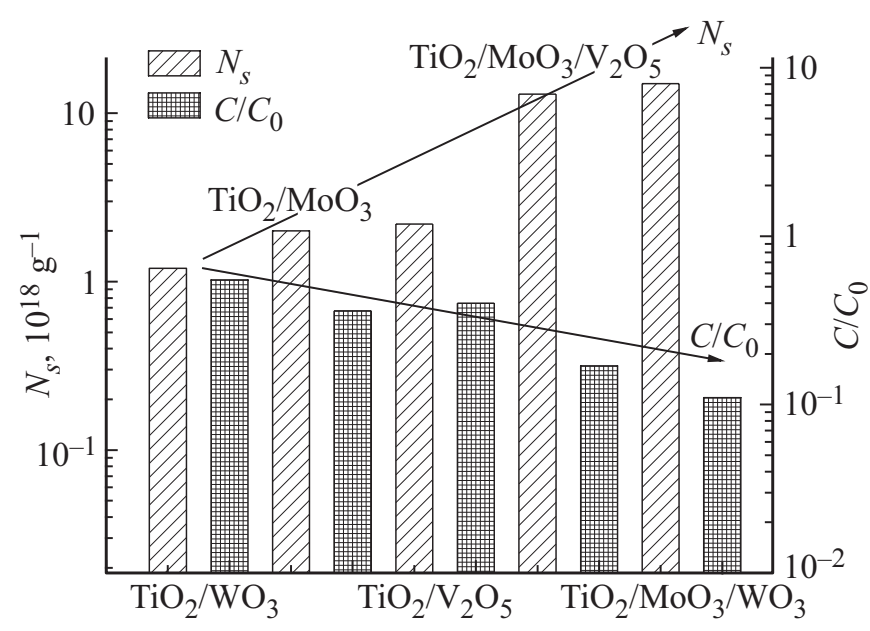

Рис. 8. Антикорреляция между концентрацией радикалов в образцах $\left(N_{s}\right)$ и концентрацией тестового красителя $\left(C / C_{0}\right)$. $C_{0}$ - концентрация красителя в момент времени $t=0$ (включение освещения), $C$ - концентрация красителя в момент $t$. 


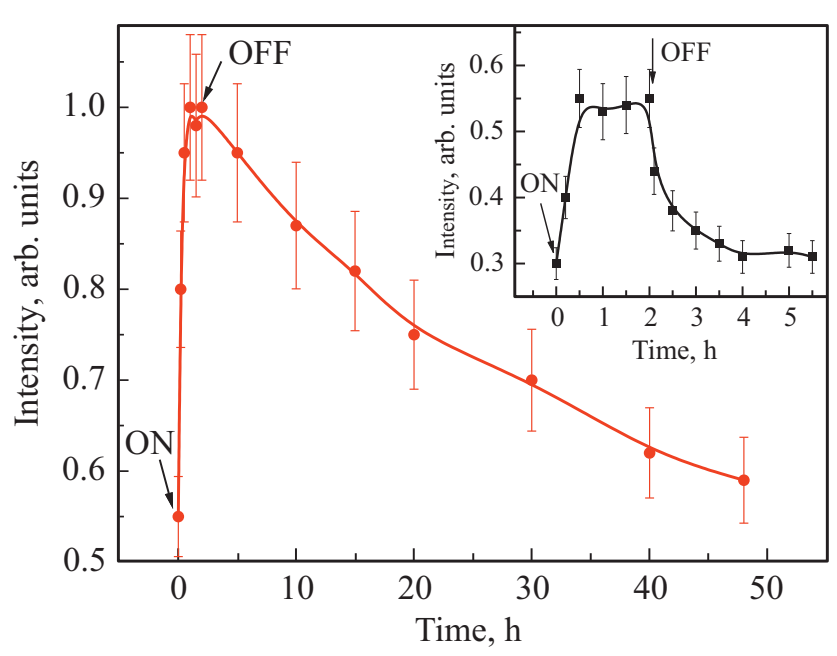

Рис. 9. Кинетика релаксации интенсивности сигнала ЭПР в $\mathrm{TiO}_{2} / \mathrm{MoO}_{3} / \mathrm{V}_{2} \mathrm{O}_{5}$ в сравнении с данными для $\mathrm{TiO}_{2}$ (на вставке). Стрелками показаны моменты включения $(\mathrm{ON})$ и выключения освещения (OFF).

ставлен на рис. 8. Другими словами, фотокаталитическая активность образцов коррелирует с величиной $N_{s}$.

Отметим, что эффект накопления заряда в исследуемых наногетероструктурах подтверждается также методом ЭПР. На рис. 9 в качестве примера показаны изменения интенсивности сигнала ЭПР при включении/выключении освещения для образцов $\mathrm{TiO}_{2} / \mathrm{MoO}_{3} / \mathrm{V}_{2} \mathrm{O}_{5}$. Для сравнения на вставке приведена соответствующая кривая для диоксида титана. Вариации интенсивности сигнала ЭПР обусловлены перезарядкой дефектных центров, т.е. переходом их из первоначально непарамагнитного в парамагнитное состояние при захвате фотоиндуцированного заряда. После выключения освещения релаксация интенсивности сигнала ЭПР в наногетероструктурах происходит крайне медленно по сравнению c $\mathrm{TiO}_{2}$, что согласуется с поведением фотокаталитических зависимостей (рис. 5). Аккумулированный на дефектах заряд, как было указано выше, расходуется постепенно.

\section{4. Заключение}

В ходе работы получены энергоэффективные фотокатализаторы, функционирующие в видимом диапазоне спектра и, кроме того, после прекращения освещения, т.е. характеризующиеся пролонгированным каталитическим действием. С помощью совокупности независимых методов исследования показано значительное увеличение чувствительности к видимому излучению наногетероструктур на основе $\mathrm{TiO}_{2}$ по сравнению с отдельно взятым диоксидом титана. В исследуемых образцах обнаружены радикалы типа $\mathrm{N}^{\bullet}$,
$\mathrm{Ti}^{3+} /$ кислородная вакансия, $\mathrm{Mo}^{5+}, \mathrm{V}^{4+}$ и $\mathrm{W}^{5+}$ (в зависимости от состава гетероструктуры). Обнаружено, что с ростом концентрации радикалов увеличивается фотокаталитическая активность наногетероструктур. Данный факт и наличие пролонгированной каталитической активности после выключения освещения могут быть обусловлены подавлением рекомбинации электронов и дырок вследствие их пространственного разделения в различных нанооксидах, входящих в состав образцов. Далее, фотовозбужденные носители заряда могут быть захвачены дефектами. После прекращения освещения аккумулированный таким образом заряд является резервуаром для образования участвующих в окислительно-восстановительных реакциях кислородных и гидроксильных радикалов в процессе адсорбции молекул кислорода и воды на поверхности нанооксидов. Установлено, что полученные материалы сохраняют свои фотокаталитические свойства длительное время.

\section{Финансирование работы}

Исследование выполнено при финансовой поддержке Российского фонда фундаментальных исследований в рамках научного проекта № 18-29-23051.

Измерения методом ЭПР и спектроскопия рассеяния выполнены на оборудовании ЦКП МГУ им. М.В. Ломоносова.

The research was carried out with the financial support of the Russian Foundation for basic research in the framework of research project No. 18-29-23051.

\section{Конфликт интересов}

Авторы заявляют об отсутствии конфликта интересов.

\section{Список литературы}

[1] X. Chen, S.S. Mao. Chem. Rev., 107, 2891 (2007).

[2] Yu. Wei, Yu. Huang, Yu Fang, Yu. Zhao, D. Luo, Q. Guo, L. Fan, J. Wu. Mater. Res. Bull., 119, 110571 (2019).

[3] J. Schneider, M. Matsuoka, M. Takeuchi, J. Zhang, Y. Horiuchi, M. Anpo, D.W. Bahnemann. Chem. Rev., 114, 9919 (2014).

[4] H. Zhang, G. Chen, D.W. Bahnemann. J. Mater. Chem., 19, 5089 (2009).

[5] E.V. Skorb, L.I. Antonouskaya, N.A. Belyasova, D.G. Shchukin, H. Möhwald, D.V. Sviridov. Appl. Catal. B, 84, 94 (2008).

[6] T.V. Sviridova, L.Yu. Sadovskaya, E.M. Shchukina, A.S. Logvinovich, D.G. Shchukin, D.V. Sviridov. J. Photochem. Photobiol. A: Chem., 327, 44 (2016).

[7] В.Б. Зайцев, Е.А. Константинова, Д.М. Дейген, М.Н. Румянцева, Е.В. Подолько, М.В. Пустовалов, П.К. Кашкаров. Вестн. МГУ. Серия 3. Физика. Астрономия, 68 (5), 49 (2013).

[8] S. Livraghi, M.R. Chierotti, E. Giamello, G. Magnacca, M.C. Paganini, G. Cappelletti, C.L. Bianchi. J. Phys. Chem. C, 112, 17244 (2008). 
[9] I.S. Pentegov, E.A. Konstantinova. Phys. Status Solidi C, 8, 1954 (2011).

[10] M. Yan, G. Li, C. Guo, W. Guo, D. Ding, S. Zhanga, S. Liu. Nanoscale, 8, 17828 (2018).

[11] E.V. Skorb, E.A. Ustinovich, A.I. Kulak, D.V. Sviridov. J. Photochem. Photobiol. A, 193, 97 (2008).

[12] E.A. Konstantinova, A.A. Minnekhanov, G.V. Trusov, V.G. Kytin. Nanotechnology, 31, 345207 (2020).

[13] Г. Кортюм, В. Браун, Г. Герцог. УФН, 85 (2), 365 (1965).

[14] K.V. Zaitsev, V.A. Tafeenko, Yu.F. Oprunenko, A.V. Kharcheva, Zh. Zhanabil, R. Suleiman, K. Lam, V.B. Zaitsev, A.V. Zaitseva, G.S. Zaitseva, S.S. Karlov. Chemistry - An Asian J., 12 (11), 1240 (2017).

[15] E.A. Konstantinova, V.B. Zaitsev, A.A. Minnekhanov, N.T. Le, P.K. Kashkarov. Crystallography Reports, 65 (1), 130 (2020).

[16] K. Byung-Hyun, P. Mina, K. Gyubong, K. Hermansson, P. Broqvist, C. Heon-Jin, L. Kwang-Ryeol. J. Phys. Chem. C, 122 (27), 15297 (2018).

[17] A. Szekeres, T. Ivanova, K. Gesheva. J. Solid State Electrochem., 7, 17 (2002).

[18] R. Sivakumar, R. Gopalakrishnan, M. Jayachandran, C. Sanjeeviraja. Curr. Appl. Phys., 7, 51 (2007).

[19] P.P. González-Borrero, F. Sato, A.N. Medina, M.L. Baesso, A.C. Bento, G. Baldissera, C. Persson, G.A. Niklasson, C.G. Granqvist, A. Ferreira da Silva. Appl. Phys. Lett., 96 (6), 061909 (2010).

[20] Yu. Wei, Yu. Huang, Yu. Fang, Yu. Zhao, D. Luo, Q. Guo, L. Fan, J. Wu. Mater. Res. Bull., 119, 110571 (2019).

[21] C. Di Valentin, G. Pacchionni, A. Selloni, S. Livraghi, E. Giamello. J. Phys. Chem. B, 109, 11414 (2005).

[22] A.I. Kokorin. In: Chemical physics of nanostructured semiconductors, ed. by A.I. Kokorin and D.W. Bahnemann (Utrecht, Boston: VSP-Brill Academic Publishers, 2003) p. 203.

[23] A. Varlec, D. Arcon, S.D. Skapin, M. Remskar. Mater. Chem. Phys., 170, 154 (2016).

[24] A. Folli, J.Z. Bloh, D.E. Macphee. J. Electroanal. Chem., 780, 367 (2016).

[25] M. Occhiuzzi, D. Cordischi, D. Gazzoli, M. Valigi, P.C. Heydorn. Appl. Catal. A, 269, 169 (2004).

[26] L. Lietti, I. Nova, G. Ramis, L. Dall'Acqua, G. Busca, E. Giamello, P. Forzatti, F. Bregani. J. Catal., 187, 419 (1999).

[27] G. Centi, E. Giamello, D. Pinelli, F. Trifiro. J. Catal., 130, 220 (1991).

Редактор Л.В. Шаронова

\section{Photo-accumulating nanoheterostructures based on titania}

\author{
E.A. Konstantinova $\mathbf{1}^{\mathbf{1}, 2,3}$, V.B. Zaitsev ${ }^{\mathbf{1}}$, E.V. Kytina ${ }^{\mathbf{1}}$, \\ A.V. Marikutsa ${ }^{4}$ \\ ${ }^{1}$ Physics Department \\ of Lomonosov Moscow State University, \\ 119991 Moscow Russia \\ 2 National Research Center „Kurchatov Institute“, \\ 123182 Moscow, Russia \\ ${ }^{3}$ Moscow Institute of Physics and Technology, \\ 141700 Dolgoprudny, Russia \\ ${ }^{4}$ Chemistry Department \\ of Lomonosov Moscow State University, \\ 119991 Moscow, Russia
}

Abstract Nanoheterostructures based on titanium dioxide synthesized by the sol-gel method were studied. Microscopy, $X$-ray diffraction, optical spectroscopy, and electron spin resonance techniques were used. All the samples under the study are characterized by a large specific surface area $\left(\sim 100 \mathrm{~m}^{2}\right.$ per $1 \mathrm{~g}$ of substance). It is established that the main types of radicals in the obtained structures are $\mathrm{N}^{\bullet}, \mathrm{Ti}^{3+}, \mathrm{Mo}^{5+}, \mathrm{V}^{4+}$, and $\mathrm{W}^{5+}$, depending on the composition of the samples. It is shown that nanoheterostructures consisting of several metal oxides have high photocatalytic activity in the visible range of the spectrum and the ability to accumulate photogenerated charge carriers. As a result, the catalytic reactions in the samples continue even after the lighting is turned off. A correlation was found between the rate of photocatalysis, the absorption spectra in the visible region, and the concentration of radicals in the studied structures. The results obtained can be used to develop energyefficient catalytic devices based on nanoheterostructures consisting of titanium, molybdenum, tungsten, and vanadium nanoxides in various combinations which operate under periodic illumination in the visible range of the spectrum. 